\title{
HUMAN FACTORS IN HIGHWAY-RAIL CROSSING ACCIDENTS: THE INFLUENCE OF DRIVER DECISION STYLE
}

\author{
Mansour Rahimi \\ Department of Industrial and Systems Engineering \\ University of Southern California \\ Los Angeles, CA 90089-0193 USA \\ mrahimi@rcf.usc.edu; \\ Najmedin Meshkati \\ Department of Civil and Environmental Engineering \\ University of Southern California \\ Los Angeles, CA 90090 USA \\ meshkati@rcf.usc.edu
}

\begin{abstract}
Summary: This paper explores the hypothesis that driver decision-making style influences highway-rail crossing accidents. To investigate this, we have designed an analysis of variance experiment with three independent variables: “driver decision style," “driver time pressure” and "intersection complexity." To simulate the driving conditions, we identified and videotaped a number of dangerous crossings in downtown Los Angeles. The tapes represented different environmental complexities and time pressures a driver experiences while crossing an intersection. The tapes were played back to the subject drivers. The subjects were classified according to their decision styles. Dependent measures were designed based on a driver's decision to cross the intersection. This paper presents the conceptual approach and the experimental design for this research.
\end{abstract}

\section{INTRODUCTION}

Published statistics indicate that the number of deaths at highway-rail crossings is the highest among rail-related fatalities (Department of Transportation, DOT, 1/11/00). Over the last five years, incidents at highway-rail crossings (including trespassing) have accounted for $93.8 \%$ of the deaths and $12 \%$ of the injuries in rail operations (DOT, 1/11/00). In 1999, we experienced approximately 3,420 highway-rail incidents and almost 400 deaths (DOT, 3/6/00). Statistically speaking, there is a collision between a train and a vehicle every 90 minutes in the U.S. Given these dreadful statistics, federal, local and private organizations have taken positive steps in improving the HRC situation. For example, states and localities working with the DOT have closed more than 33,000 hazardous grade crossings since 1991, and subsequently, there have been 30\% fewer highway-rail crossing collisions since 1993, 33\% less highway-rail crossing fatalities, and a 31\% reduction in highway-rail crossing injuries (Barry, 1999). Nevertheless, each year, HRC collisions cost the society about 1.8 billion dollars in medical costs, insurance payments, legal fees, and damages to railroad property (Meeker, 1997). 


\section{Causes and Current Approaches to HRC Safety}

An in-depth look at the literature in this area has revealed a number of influential factors in HRC accidents. A recent HRC accident report of the Los Angeles County Blue Line has detailed sixteen "contributing factors" for their accidents (LAC/MTA, 1999). One can see that the "human factors" related factors play an important role in these accidents. For example, Wilner (1998) reported that over one-third of rail accidents and 80\% of train collisions are caused by human error. Moreover, a recent study in Japan looked at HRC accidents in a comprehensive and multi-factorial approach. (Anandarao and Martland, 1998). Based on their classification, it was found that the leading cause of the crossing accidents was the driver's "Ignorance of Warning." Indications are that they did not notice the warnings in time to stop. It is also conceivable to say that some drivers chose to ignore the warning and voluntarily enter the crossing. By adding these to a generic model of HRC accidents offered by Tustin et al., 1986, one can generate a large number of influential factors classified as: vehicle (size, maintenance), highway (surface, geometry, traffic load, environmental conditions), driver (risk perception, reaction time), train (speed, flagging, brake time), and crossing feature (warning systems, visibility, trespassing, enforcement).

\section{Beyond Technological fixes: Driver Decision Styles}

Due to the complexity of studying some of these variables, we do not know of the relative importance of the abovementioned variables influencing HRC accidents with statistical accuracy. The field continues to support and fund technological fixes to improve HRC safety.

Nevertheless, a number of NTSB accident reports (2000, Vol. 1 and 2) hint at the possibility that the driver's decision style might be as important as his/her interactive behavior. Is it possible that warning cues, roadway or track conditions, excessive signage at intersections, and sun glare affecting visibility could interact with the driver decision to cross or not to cross?

\section{METHODOLOGY}

From the previous discussion, we see that HRC accident studies have not focused on the role of driver decision-making. We believe that the decision styles of the drivers have a significant impact on the way in which the HRC actions are motivated. Decision styles are the way by which individuals receive, store, process, and transmit information for action (Driver, 1983). Literature on driver decision-making has primarily focused on the "normative" approaches. In this research, however, we focus on a "descriptive-differential” approach, which matches the driver's decision style, driving task demands, and then determine the fit to the environmental factors of HRC. The descriptive-differential approach allows an accurate classification of different types of decision processes, decision-makers, tasks, information requirements and environmental factors (Driver, 1983).

In this research we refer to decision style as (1) the manner in which the driver reacts to a given crossing situation, or (2) the manner of interaction with other elements of the environment. This approach suggests that environmental variables (e.g., time pressures and mental load) affect the complexity of information processing behavior of the driver. In this respect, the decisionmaking differs among drivers in two key dimensions: 
- Complexity or amount of information used: This is divided into moderately low or "satisficer" (designated by S), and high or "maximizer" (designated by M)

- Focus or number of alternatives generated from the information presented: This could be a single alternative (SI), or a multiple alternative (MU) simultaneously or within a very short time.

Based on this classification, the two dimensions generate a four-fold table (below), showing four basic decision styles (Driver, Brousseau, and Hunsaker, 1993):

\begin{tabular}{|l|l|l|}
\cline { 2 - 3 } \multicolumn{1}{c|}{} & Satisficer (S) & Maximizer (M) \\
\hline SI & Decisive & Hierarchic \\
\hline MU & Flexible & Integrative \\
\hline
\end{tabular}

The Decisive driver is one who uses a small amount of information to generate a "good enough" decision. The Flexible driver is one who employs a minimum amount of information to reach a decision. The Hierarchic driver requires a very high use of all potentially available information to meticulously generate one "best solution" for the decision on hand. The Integrative driver also uses a large amount of information, but simultaneously generates a number of possible solutions for implementation. (Every individual has at least one “ dominant” decision style normally exhibited under moderate environmental load and a backup decision style for under extreme load conditions.) In the context of HRC decisions, it is difficult (if not impossible) to produce an accurate definition of a "good" decision. The question here is whether we can define the most appropriate match of situation and decision process. In other words, what should be considered is the "fit" between driver's situational assessment and his/her decision to cross. The following examples highlight the role of decision style in HRC accidents (e.g., deciding to pass over a HRC when a train is outside the perceived minimum time to collision). These examples are based on our direct experience investigating the role of decision styles on operator performance [Meshkati, Buller, Tan, and Lesjak, (1999); Meshkati, Buller, and Azadeh (1994)] and the role of physical and environmental characteristics of intersection on driver's left-turn maneuvers [Rahimi, Briggs, and Thom (1990); Hancock, Wulf, Fasnacht, Rahimi (1991)].

- Decisive drivers may take a single prompt decision (based on just sufficient amount of information from the crossing environment) to cross without a second thought.

- Flexible drivers, having multiple equally attractive choices, may start to implement one decision (e.g. to cross) and then switch to another choice.

- Hierarchic drivers, having done an elaborate analysis of all available HRC information, may make one decision for safe crossing.

- Integrative drivers, searching for more information and coming up with multiple choices, may take more time to cross and may change their driving behavior while crossing.

Therefore, decision styles are important factors to understanding of HRC driving activities. We are able to measure these styles with instruments that have had extensive testing and validation. One such instrument is the Driver Decision Style Exercises, also known as DDSE instrument (Suedfeld and Streufert, 1966; Driver and Streufert, 1969; Driver, 1983). More than 400,000 individuals have used this "paper and pencil" instrument, which is now being offered on the Internet at http://www.futurestep.com/. It measures the actual decision style of individual when making decisions in a non-self-conscious manner (called “operating decision style”). It also offers a high reliability, with test-retest correlation index ranging from 0.62 to 0.86 . 


\section{Experimental Design}

In order to study the effects of each decision style on the HRC safety factors, we have designed an experimental evaluation methodology, using analysis of variance approach. The following table shows the independent variables grouped into decision styles and system variables.

Each system variable (independent variable) is nested with two levels of "high" and "low." The variables are:

\begin{tabular}{|c|c|c|c|}
\hline & $\begin{array}{l}\text { Decision style } \\
\text { as Grouping } \\
\text { Variable } \\
\text { (GVi) } \Downarrow\end{array}$ & & \\
\hline \multirow[t]{5}{*}{$\begin{array}{l}\text { Nested System } \\
\text { Variables } \\
(N S V i j) \Rightarrow \\
\end{array}$} & & $\begin{array}{l}\text { TP } \\
(\mathrm{H}, \mathrm{L})\end{array}$ & $\begin{array}{l}\text { EC } \\
(H, L)\end{array}$ \\
\hline & Decisive & $\mathrm{S}_{\mathrm{ij}} \rightarrow$ & \\
\hline & Flexible & & \\
\hline & Integrative & & \\
\hline & Hierarchical & & \\
\hline
\end{tabular}

Time Pressure (TP) and Environmental Complexity (EC). The subjects $\left(\mathrm{S}_{\mathrm{ij}}\right)$ are licensed drivers assigned to cells i (between-subject design) and $\mathrm{j}$ (within-subject design). The subjects will be randomly assigned to each cell to reduce learning effects.

We have videotaped actual scenes from inside an automobile, while crossing a high-incident intersection in downtown Los Angeles. Each session playback represents a cell within our nested design. Ten subjects will be assigned to each cell (total of 40). We are in the process of running the experiment and the preliminary results will be presented at the conference.

\section{ACKNOWLEDGEMENT}

This project was funded by the Metropolitan Transportation Research Center (Metrans) and CalTrans. The student support was provided by Laurel Chen, Sahar Shayesteh-Mehr and Kidra Shadroo. All opinions expressed here are those of the authors only.

\section{REFERENCES}

Anandarao, S. and C. Martland, 1998. Level-Crossing Safety on East Japan Railway Company: Application of Probabilistic Risk Assessment Techniques. Transportation, 25(3): 265-286.

Barry, P., 1999. U.S. Transportation Secretary Slater Conducts Roundtable Meeting on Highway-Rail Crossing Safety. http://www.itsa.org/85256201003EFA03/0/ D4878AF071 A1778C85256752006B35E6?Open.

Department of Transportation, Highway-Rail Crossing and Trespasser Facts: Always Expect a Train, 1/11/00. www.fra.dot.gov/o/public/factoid.htm.

Department of Transportation (DOT) Railroad Accident/Incident data, 3/6/00. http://safetydata.fra.dot.gov/officeofsafety.

Driver, M.J. (1983). Decision styles and organizational behavior: Implications for academia. The Review of Higher Education, 6(4), 387-406.

Driver, M.J., Brousseau, K. R., \& Hunsaker, P.L. (1993). The Dynamic Decision Maker: Five Decision Styles for Executive and Business Success. San Francisco, CA.: Jossey-Bass. 
Driver, M., and S. Streufert (1969). Integrative complexity, Administrative Science Quarterly, 14, 272-285.

Hancock, P.A., Wulf, G., Fasnacht, P., and Rahimi, M. (1991). Investigations into vehicle conspicuity: Car-driver behavior during differing driving maneuvers. Accident Analysis and Prevention, 22(3), 274-282.

Kady, M. and P. Shloss, 1995. $4^{\text {th }}$ Annual Meeting: Electronic Messaging Using VRC.

Los Angeles County Metropolitan Transportation Authority (LAC/MTA), Long Beach Blue Line, Grade Crossing Safety Improvement Program, 1997. Photo Enforcement at Long Beach Blue Line Grade Crossings. California DOT, Public Transportation, Ridesharing, ad Rail Brach, Sacramento, CA (December 31).

Los Angeles County Metropolitan Transportation Authority (LAC/MTA), Metro Blue Line, Grade Crossing Safety Improvement Program, 1999. Summary of Metro Blue Line Train/Vehicle and Train/Pedestrian Accidents (7/90-9/99). Risk Management Department (October 29).

Meeker, F., 1997. A Comparison of Driver Behavior at Railroad Grade Crossings With Two Different Protection Systems. Accident Analysis and Prevention, 29(1): 11-16. 1997 Projects Book: Railroad Crossing Vehicle Proximity Alert System, 2/1/00. http://www.itsa.org/852564980079857D/0/56A8582E677DCA718525649800677A7D?Ope n.

Meshkati, N., Buller, B.J., Tan, W.M, and Lesjak, B. (1999, June). Research Validating a Model of the Effect of Operator Information Processing Behavior on Performance while Using a Traditional and Ecological User Interface for a Nuclear Power Plant. Prepared for the U.S. Nuclear Regulatory Commission (Contract No. NRC 04-91-102). Los Angeles, California: University of Southern California.

Meshkati, N., Buller, B.J. and Azadeh, M.A. (1994, August). Integration of Workstation, Job, and Team Structure Design in the Control Rooms of Nuclear Power Plants: Experimental and Simulation Studies of Operators' Decision Styles and Crew Composition While Using Ecological and Traditional User Interfaces. Volume I: Technical Report, Volume II: Appendices, Prepared for the U.S. Nuclear Regulatory Commission (Contract No. NRC 0491-102). Los Angeles, California: University of Southern California.

National Transportation Safety Board (NTSB) Safety at Passive Grade Crossings: Volume 1 Analysis, 1/24/00. www.ntsb.gov/Publictn/1998/SS9802.pdf.

National Transportation Safety Board (NTSB) Safety at Passive Grade Crossings: Volume 2 Case Summaries, 1/22/00.

Rahimi, M., Briggs, R.P., and Thom, D.R. (1990). A field evaluation of driver eye and head movement strategies toward environmental targets and distractors. Applied Ergonomics, 21(4), 267-275.

Railroad Crossing and Trespassing Child Facts, 1/11/00. www.fra.dot.gov/o/public /childfact.htm.

Suedfeld, P., and S. Streufert (1966). Information search as a function of conceptual and environmental complexity, Psychonomic Science, (cited in: Driver, M. and A.J. Rowe 
PROCEEDINGS of the First International Driving Symposium on Human Factors in Driver Assessment, Training and Vehicle Design

(1978). Decision-Making Styles: A New Approach to Decision Making, Chapter 6, pp. 141182).

Tustin, B.H., H. Richards, H. McGee and R. Patterson, 1986. Railroad-Highway Grade Crossing Handbook (2 ${ }^{\text {nd }}$ Edition), Report No. FHWA TS-86-215, Federal Highway Administration, Washington, D.C.: 273.

Wilner, F. 1998. Asleep at the Throttle? Journal of Commerce Inc., May: 14. 